\title{
Banco de leite humano e Estratégia Saúde da Familia: parceria em favor da vida
}

\author{
Human milk bank and the Family Health Strategy: partnership for life

\section{Banco de leche humana y Estrategia de Salud Familiar: asociación em favor de la vida}

Fernanda Darliane Tavares de Luna. Secretaria Municipal de Saúde de Guarabira (SMS-Guarabira). Guarabira, PB, Brasil. fernandarliane@hotmail.com (Autora correspondente)

José Danúzio Leite Oliveira. Secretaria Municipal de Saúde de Areia (SMS-Areia). Areia, PB, Brasil. danuzioleite@yahoo.com.br

Lorena Rafaella de Mello Silva. Secretaria Municipal de Saúde de Alagoa Grande (SMS-Alagoa Grande). Alagoa Grande, PB, Brasil. Iorena_rafaella.

enf@hotmail.com

\section{Resumo}

Objetivo: resgatar os aspectos da relação entre os Bancos de Leite Humano (BLH) e a Estratégia Saúde da Família (ESF). Métodos: revisão integrativa da literatura, com abordagem descritivo-exploratória dos textos. As buscas foram realizadas nas bases de dados da Biblioteca Virtual em Saúde (BVS) e da SciELO, com os seguintes descritores: leite humano, bancos de leite, doações, pré-natal e programa saúde da família. Foram incluídos artigos publicados entre os anos de 2000 e 2011, em português, inglês e espanhol. Resultados: foi evidenciada uma precariedade dos conhecimentos dos profissionais da ESF sobre os BLH, o que reflete um trabalho incipiente durante o pré-natal, com abordagem apenas dos aspectos superficiais dos BLH, o que não é suficiente para captar maiores números de doadoras. Observou-se a inexistência de uma co-responsabilidade entre essas instituições na promoção do aleitamento materno. Conclusão: faz-se necessário estabelecer parcerias efetivas entre a ESF e os BLH para a sensibilização das nutrizes, proporcionando o aumento do número de doadoras, auxiliando na consolidação da atuação dos BLH. São poucas as referências abordando 0 assunto, fato que sugere a necessidade de mais estudos sobre 0 tema.

\section{Abstract}

Objective: to review aspects of the relationship between Human Milk Banks (HMB) and the Family Health Strategy (FHS). Methods: integrative literature review, with descriptive and exploratory approach to the texts. Searches were conducted in the databases of the Virtual Health Library and of the SciELO with the following keywords: human milk, milk banks, donations, prenatal care and family health program. We included articles published between the years 2000-2011, in Portuguese, English and Spanish. Results: the results showed a precarious knowledge of FHS professionals about HMB, which reflects an incipient work during prenatal care, with only the superficial aspects of HMB being covered, which are not sufficient to attract a greater number of donors. We noted a lack of co-responsibility between these institutions in promoting breastfeeding. Conclusion: it is necessary to establish effective partnerships between the FHS and HMB to raise awareness of the mothers, providing increased number of donors and helping to consolidate the activities of HMB. There are few references addressing this issue, which suggests the need for more studies.

\section{Resumen}

Objetivo: revisar los aspectos de la relación de Bancos de Leche Materna (BLM) y la Estrategia de Salud Familiar (ESF). Métodos: revisión integradora de la literatura, con enfoque descriptivo y exploratorio de los textos. Se realizaron búsquedas en las bases de datos de la Biblioteca Virtual en Salud (BVS) y SciELO, con los siguientes descriptores: leche humana, bancos de leche, donaciones, prenatales y programas de salud familiar. Se incluyeron artículos publicados entre los años 2000-2011, en Portugués, Inglés y Español. Resultados: los resultados mostraron un conocimiento precario de los profesionales de la ESF sobre bancos de leche materna, lo que refleja un trabajo incipiente durante la aproximación prenatal, sólo con los aspectos superficiales de bancos de leche materna, lo que no es suficiente para captar un mayor número de donantes. Hemos tomado nota de la falta de corresponsabilidad entre estas instituciones en la promoción de la lactancia materna. Conclusión: es necesario establecer asociaciones eficaces entre la ESF y bancos de leche materna para aumentar la conciencia de las madres y para aumentar la cantidad de donantes, ayudando a consolidar las actividades de los bancos de leche materna. Hay pocas referencias que tratan el tema, lo que sugiere la necesidad de realizar más estudios.

Como citar: Luna FDT, Oliveira JDL, Silva LRM. Banco de leite humano e estratégia saúde da família:
Palavras-chaves:

Bancos de Leite Leite Humano Estratégia Saúde da Família

Keywords:

Milk Banks Milk, Human Family Health Strategy

Palabras clave: Bancos de Leche Leche Humana Estrategia de Salud Familiar

Fonte de financiamento: Faculdades Integradas de Patos.

Parecer CEP:

não se aplica.

Conflito de interesses: declararam não haver Recebido em: 19/09/2013. Aprovado em: 11/09/2014. 


\section{Introdução}

O leite materno é o alimento básico para o recém-nascido. Ele oferece benefícios fisiológicos, com quantidades adequadas de nutrientes, fatores imunogênicos que representam a primeira imunização passiva da criança, além de benefícios psicológicos e afetivos, já que o ato de amamentar é um momento de entrega e de aproximação do binômio mãe e filho.

O leite humano contém carboidratos, proteínas, lipídios, fatores imunogênicos e minerais. Essa composição varia de acordo com a fase da lactação, adaptando-se naturalmente às carências de cada fase do crescimento e desenvolvimento da criança. Essa particularidade da composição, na qual coexistem especificidade e complexidade, faz do leite humano um alimento único, impossível de ser copiado em fórmulas comerciais. ${ }^{1}$

O leite humano tem importância fundamental para o crescimento, desenvolvimento e manutenção da saúde da criança, que vem sendo cada vez mais reconhecida. Hoje, a recomendaçâo do leite materno para crianças recém-nascidas, incluindo os recém-nascidos pré-termo e de baixo peso, é unânime. ${ }^{2}$ Nesse contexto, ganham espaço as discussóes sobre a temática dos Bancos de Leite Humano (BLH).

Os BLH não são apenas postos de coleta, estocagem e distribuição de leite, mas se configuram como uma importante estratégia para promoção, proteçấo e apoio à prática da amamentação. Uma das prioridades dos bancos de leite é atender os RNs pré-termo e de baixo peso que ficaram privados da amamentação direta no peito, promovendo a redução da mortalidade infantil nesse público. ${ }^{3}$

Em pleno processo de expansão e consolidaçáo, os BLH ganham cada vez mais reconhecimento. Por iniciativa conjunta do Ministério da Saúde e da Fundação Oswaldo Cruz, os BLH passam a ser organizados e estruturados em rede, com a criação da Rede Nacional de Bancos de Leite Humano (RNBLH) em 1998. ${ }^{4}$

A RNBLH é uma rede de bancos e postos de coleta, bem estruturada e descentralizada, com unidades em todas as regiōes do país. Sua missão é a promoção da saúde da mulher e da criança, mediante a integração e a construção de parcerias com órgãos federais, iniciativa privada e sociedade. ${ }^{5}$

Hoje, o Brasil conta com 200 BLH e 92 postos de coleta distribuídos em todas as regiôes do país. No nordeste, são 48 BLH e 26 postos de coleta. Destes, 6 BLH e 12 postos de coleta estão no estado da Paraíba. ${ }^{5}$

Apesar de a RNBLH ser bem estruturada e com números representativos de BLH e postos de coleta, é visível a discrepância entre a quantidade de leite doado e a demanda existente. No ano de 2010, a RNBLH teve a participação de 141.674 doadoras e 134.733 receptores, com um volume de 148.653 litros de leite doados e 115.553 litros de leite distribuídos. Quando analisados dados da região nordeste, observamos demandas superiores à disponibilização: 28.607 doadoras para 44.214 receptores. ${ }^{5}$

$\mathrm{O}$ volume de leite humano disponível graças à doaçáo ainda é insuficiente para suprir a real demanda existente. O maior desafio atualmente para a RNBLH é garantir o fornecimento, de maneira segura e sustentável, para todos os RNs que necessitem do leite humano por meio das doaçóes. ${ }^{1}$

Assim, surgem as seguintes indagaçôes: como as mulheres doadoras e doadoras em potencial estão sendo incentivadas para a doação? Será que a temática está sendo trabalhada durante o pré-natal?

No nível básico da atenção em saúde, os profissionais da Estratégia Saúde da Família (ESF) oferecem uma atenção pré-natal e puerperal buscando a qualidade e a humanização, incluindo, assim, açôes de promoção e prevenção para a saúde do binômio mãe-filho. ${ }^{6}$ Nessa ótica, merece destaque a promoção do aleitamento materno.

É interessante saber se está acontecendo a efetiva parceria entre os BLH e a ESF, já que, na temática aleitamento materno, apesar dos papéis distintos, suas missóes se confundem.

Neste trabalho, nos propomos a fazer o resgate nas bases de dados científicos das literaturas que versem sobre a temática para delas extrair os aspectos explorados sobre a relação entre os BLH e a ESF.

\section{Materiais e métodos}

Trata-se de uma revisão integrativa da literatura, de caráter descritivo-exploratório e abordagem qualitativa. Com a finalidade de colocar o pesquisador em contato direto com tudo o que foi escrito, dito ou filmado sobre determinado assunto, optou-se por uma pesquisa bibliográfica abrangente, considerando-se também fontes secundárias do conhecimento: publicaçôes avulsas, boletins, jornais, revistas, livros, pesquisas, monografias, teses, material cartográfico, dentre outros, até mesmo meios de comunicação orais (rádio, gravaçóes em fita magnética e audiovisuais, filmes e televisão). 
Desta forma, foram realizadas buscas das literaturas disponíveis nas bases de dados BVS/Aleitamento Materno, SciELO, Ministério da Saúde e Fiocruz, durante os meses de outubro, novembro e dezembro de 2012. Os descritores utilizados foram: leite humano, bancos de leite, doaçôes, pré-natal e programa saúde da família.

Como critério de inclusão, adotou-se a delimitação temporal das publicaçôes sobre a temática de 11 anos (entre 2000 e 2011), o que permitiu visualizar a expansão e consolidação dos BLH e da ESF. Utilizamos publicações em português, inglês e espanhol que versavam sobre o banco de leite humano, doação e doadoras, e que tivessem sido desenvolvidas no Brasil. Foram excluídos os artigos que não se enquadravam na linha temporal estabelecida, que se restringiam a aspectos técnicos de composição do leite humano, ou que abordavam aspectos técnicos e históricos sobre o BLH.

A busca nas bases de dados localizou 403 referências. Ao ser estabelecido o limite espaço-temporal, o número reduziu para 23, sendo 03 destas referências duplicadas, restando 20 títulos pré-selecionados para a análise. Após a leitura criteriosa dos títulos e resumos, 11 artigos foram selecionados por atender ao objetivo proposto em nosso estudo. Em seguida, foram acrescidas 04 literaturas oficiais (01 portaria e 03 Manuais do Ministério da Saúde), resultando em 15 títulos selecionados para análise e interpretação na produção do conhecimento trabalhado. Não foi localizado nenhum material audiovisual. A Figura 1 ilustra a estratégia de seleção.

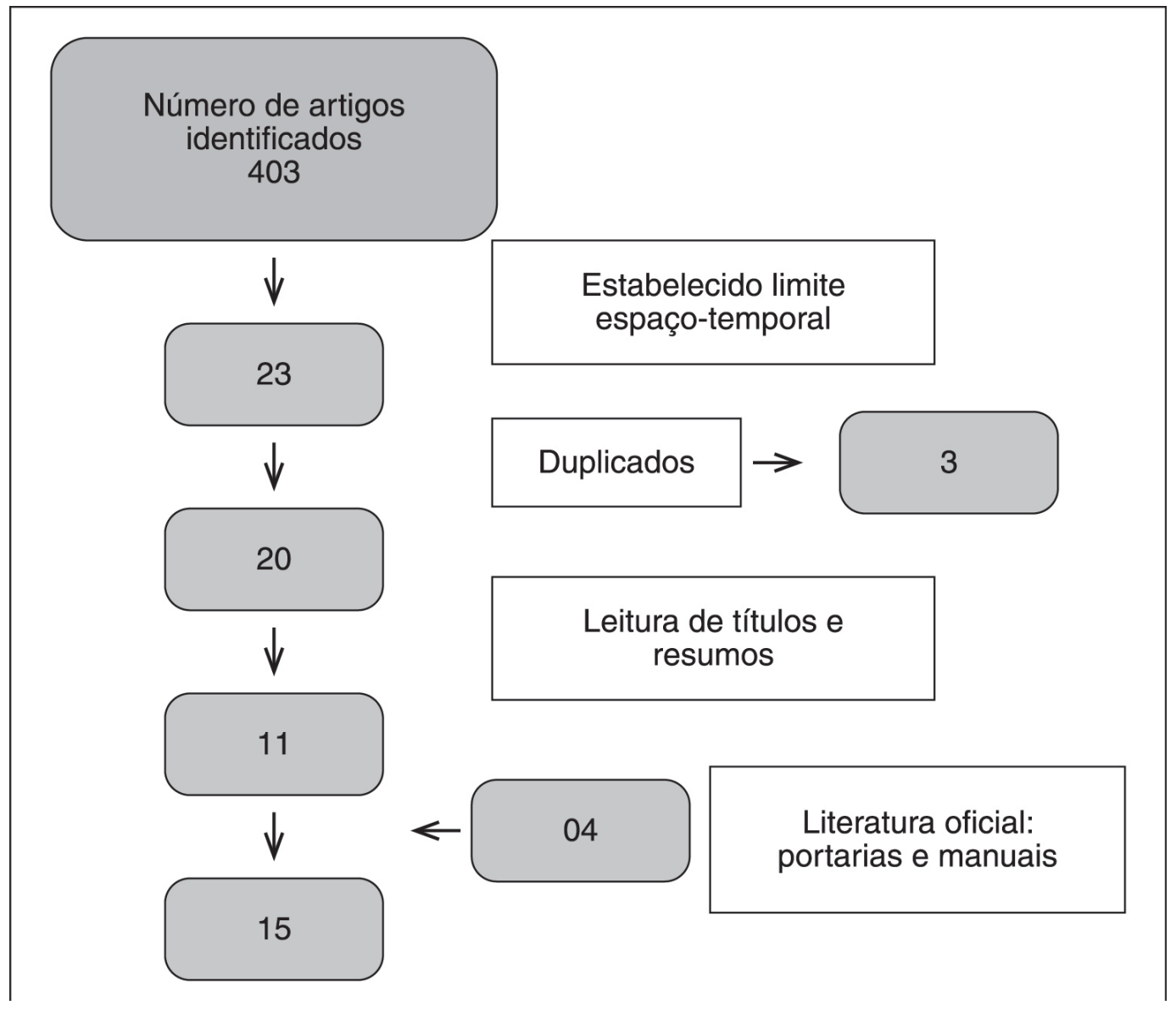

Figura 1. Estratégia de seleção das publicações utilizadas na revisão integrativa.

\section{Resultados e discussão}

O leite materno é o alimento mais adequado para os recém-nascidos e serve de referência para se estabelecerem os requerimentos nutricionais desta fase da vida. Contém em proporçóes adequadas os nutrientes necessários para o início da vida, contribuindo para o crescimento e o desenvolvimento infantis. Por essas condiçóes, o leite humano desempenha um papel de fundamental importância no cenário de redução de mortalidade infantil e neonatal. ${ }^{2}$ 
O aleitamento materno exclusivo é indicado pelo Ministério da Saúde durante os primeiros seis meses de vida. Devem se beneficiar do leite materno os $\mathrm{RN}$ a termo com bom estado de saúde, que sugam diretamente no seio da mãe, e os $\mathrm{RN}$ pré-termo ou com complicaçóes do estado geral de saúde que, apesar de impossibilitados de mamar ao seio, pois essa atividade lhe exigiria esforços e gastos excessivos de energia, podem se beneficiar deste alimento por meio da disponibilização pelos BLH. $^{7}$

A importância adquirida pelo aleitamento materno é táo significativa que, durante o período gestacional, algumas das principais inquietaçôes das mulheres giram em torno de questôes como: "Serei capaz de amamentar?", "Meu leite será suficiente?", "Quais as dificuldades que irei enfrentar?", dentre outras. ${ }^{8}$

Durante o pré-natal, período em que acontece o maior contato dos profissionais das ESF com a população feminina por conta dos encontros mensais ou até em intervalos menores conforme a necessidade, algumas destas questóes são discutidas. ${ }^{9}$

No decorrer do pré-natal, acontece um trabalho clínico associado a atividades educativas. Autores complementam o pensamento afirmando que o pré-natal configura um belo cenário para as orientaçóes sobre amamentação e doaçáo de leite materno para os BLH. ${ }^{9}$

A sensibilização para a importância da doação de leite tem momento privilegiado durante as consultas de pré-natal. Gestantes que recebem informaçôes e são bem orientadas sobre aleitamento e sobre doação de leite compreendem melhor a relevância em termos de saúde pública do ato de doar e desenvolvem a capacidade de reconhecer condiçóes que potencializam a doação. ${ }^{10}$

Muitas das questôes sobre o aleitamento materno são realmente trabalhadas. No entanto, por vezes são esquecidas questôes como os motivos para as crianças serem privadas do aleitamento no peito e as condutas a seguir nestas situaçóes, assim como condutas para máes que terão leite em excesso e para a prevençáo de complicaçóes como a mastite. Esses assuntos nos remetem aos BLH.

Surgindo a partir da década de 1940, os bancos de leite humano no Brasil ganharam maior impacto com a implantação do Programa Nacional de Incentivo ao Aleitamento Materno (PNIAM), em 1981. Porém, até hoje, ainda vêm se firmando como fator de relevância para a Saúde Pública. ${ }^{5}$

No Brasil, o primeiro banco de leite humano, no Instituto Fernandes Figueira, foi instalado em 1943 na cidade do Rio de Janeiro e encontra-se em atividade até os dias atuais, sendo o centro de referência nacional para os BLH no país. ${ }^{4}$

Os BLH são uma importante estratégia de promoção, proteção e apoio ao aleitamento materno. Sua principal função é o apoio às mulheres que desejam amamentar seus filhos que, por motivos diversos, estáo privados do aleitamento direto no peito. Além disso, trabalham para conseguir prolongar a amamentação das crianças no seio materno, tendo a meta de aleitamento exclusivo durante os primeiros seis meses de vida. Eles oferecem também apoio para as mulheres que apresentam dificuldade durante a lactação. ${ }^{3}$

Os objetivos específicos dos BLH são: atuar na coleta do leite materno, possibilitando um estoque que atenda a sua demanda; organizar o cadastramento das doadoras para possibilitar a coleta domiciliar; distribuir o leite, controlando a autenticidade e as propriedades bacteriológicas do leite logo após ocorrer a sua coleta; conservar e estocar o leite coletado; e propiciar às doadoras e a seus familiares melhores condiçóes de atendimento médico, nutricional e social. ${ }^{7}$

Os BLH trabalham com estocagem do leite conforme técnicas e normas estabelecidas pela resolução RDC, No171, de 04 de setembro de 2006. O leite estocado é proveniente de doação de lactantes. ${ }^{3}$

Podem ser consideradas doadoras as nutrizes saudáveis que apresentam secreção láctea superior às exigências de seu filho e que se dispóem a doar o excedente por livre e espontânea vontade. ${ }^{3}$

Também são doadoras as lactantes que se encontram impedidas de amamentar seus filhos diretamente no seio, por motivos ligados à saúde dos mesmos ou à sua própria saúde, sendo assim incompatíveis com a amamentação, mas não com a lactação. As nutrizes que têm seus filhos internados por motivos diversos podem estimular a lactação por meio da ordenha, e doar o leite ao banco. ${ }^{5}$

Os motivos que levam uma nutriz a doar são: altruísmo, doação como expressão de ajuda, excesso de produção láctea, conhecimento de um bebê que esteja precisando, ou informação de que o BLH esteja precisando. ${ }^{10}$

O comportamento das nutrizes durante o processo de decisáo pelo ato de doar sofre também influência direta das orientaçôes fornecidas pelos profissionais de saúde. ${ }^{4}$ Estudo realizado no Distrito Federal, com 36 mulheres doadoras regulares de leite humano, evidenciou que o apoio institucional foi fundamental para que mulheres se tornassem doadoras, e o incentivo dos profissionais de saúde teve papel relevante na decisão. ${ }^{10,11}$ 
Os mesmos autores revelaram que 47,25\% das participantes consideraram imprescindível o apoio dos profissionais de saúde para se sentirem motivadas para a prática de doação. ${ }^{10}$

Quanto às instituiçóes que ofereciam apoio, os hospitais/maternidades e os BLH foram lembrados pelas mulheres. As unidades básicas de saúde não foram referenciadas na pesquisa. ${ }^{10,11}$ No entanto, dentre as propostas relatadas pelas participantes do estudo para melhorar o apoio institucional, foi sugerida a disponibilização de informaçôes sobre a doação durante as consultas de pré-natal pelos profissionais da ESF. ${ }^{11}$ Apesar de voluntária, a doação segue normas pré-estabelecidas. O Artigo $5^{\circ}$ da portaria regulamentadora dos BLH no Brasil estabelece que: "É vedada a comercialização dos produtos coletados, processados e distribuídos pelo Banco de Leite Humano e pelo Posto de Coleta de Leite Humano". 3

Toda lactante interessada na doação deve passar por triagem para que o BLH estabeleça o controle clínico desta doadora com a finalidade de proteger a saúde da mesma e a do receptor. O leite doado deve ter passado por condiçóes ideais de manipulação, ordenha, estocagem, conservação e transporte. ${ }^{3}$

Após chegar ao banco, o leite recebe tratamento de pausterização para inativar sua flora microbiota sem alterar a qualidade. Segue-se um rígido controle de qualidade até sua distribuição com qualidade certificada. ${ }^{3}$

O que se vê, ainda hoje, é a estocagem do banco de leite bem incipiente quando comparada à sua demanda, impedindo a obtenção de maiores impactos sobre a redução da mortalidade neonatal e infantil. Neste aspecto, é visível a necessidade de maior sensibilização das nutrizes para a doação. ${ }^{8}$

Considera-se imprescindível que os BLH disponham de leite humano em quantidades adequadas para a sua demanda, nos momentos de urgência. As doaçóes voluntárias são indispensáveis para dar continuidade ao projeto dos BLH, os quais viabilizam a manutenção do aleitamento natural para os grupos-alvo. ${ }^{12}$

Para o Ministério da Saúde, a manutenção do aleitamento materno no Brasil ainda tem muitas limitaçóes, e um dos problemas prioritários é a falta de conhecimento e de sensibilização dos profissionais de saúde sobre a lactação e sobre os BLH. ${ }^{13}$

Quando indagados sobre o serviço oferecido pelos BLH, os profissionais da ESF referenciaram o BLH como órgão responsável pela captaçáo e distribuição de leite humano, desconhecendo seu papel fundamental na promoçáo do aleitamento materno. Essa falta de conhecimento mais profundo é refletida nos baixos percentuais de encaminhamentos ao serviço, já que apenas 57\% dos profissionais de nível superior já o fizeram ao menos uma vez. ${ }^{13}$

O Ministério da Saúde reconhece essa carência e aborda o tema dos BLH em suas publicaçóes destinadas aos profissionais das ESF, estabelecendo como diretriz a ser trabalhada e abordada também nas unidades básicas de saúde. Um exemplo é $O$ Guia prático do agente comunitário de saúde publicado em 2009. Os agentes comunitários de saúde (ACS) são personagens importantes na integração dos serviços de saúde da atenção primária com a sociedade, e o guia foi elaborado para fornecer subsídios para o trabalho desses profissionais. ${ }^{14}$

Conforme o manual, o ACS deve orientar as gestantes e puérperas sobre a doação de leite humano, abordando questōes como: "quem pode doar?", "onde doar?" e "onde buscar maiores informaçóes?”. Além disso, deve orientar sobre o rigor asséptico durante a ordenha e estocagem, oferecer apoio às mulheres que já são doadoras e incentivar as que ainda não doam. A Unidade de Saúde da Família deve ser referência para a população adscrita na área para fornecer informações e facilitar o acesso aos BLH. ${ }^{14}$

As açôes educativas e de acolhimento às mulheres realizadas durante o pré-natal são fundamentais para a captação de doadoras. ${ }^{10}$ Vale ressaltar a importância da preparação dos profissionais de saúde; eles devem estabelecer uma comunicação centrada na nutriz e promover o conhecimento adequado sobre o aleitamento materno e a doaçáo de leite. ${ }^{12}$

Contudo, apesar de ser inquestionável que o leite materno muitas vezes é vital para a recuperação, sobrevida e qualidade de vida dos RNs com alto e médio risco, privados do aleitamento ao seio materno, Felipe e Almeida (2005) ${ }^{9}$ observaram que os enfermeiros e os médicos das ESFs não estão engajados na promoção e incentivo à doação de leite materno para os $\mathrm{BLH}$, pois apenas $26,9 \%$ das puérperas entrevistadas em seu estudo afirmaram ter recebido alguma orientação sobre doação durante o contato com esses profissionais.

Ratificando a afirmação anterior, Alencar e Seidl $(2010)^{11}$ mostram em seu estudo um percentual de 44,4\% das lactantes que não haviam recebido nenhuma informação sobre doação do leite humano antes de seus bebês terem nascido. Mostram ainda um percentual de 36,4\% dessas mulheres afirmando não se sentirem apoiadas pelas unidades básicas de saúde para a doação. 
Quando há abordagem sobre os BLH e doação durante o pré-natal, as informaçôes são muito pontuais; as discussões limitam-se somente a apresentar os BLH como serviços que recebem leite de mães para doar para filhos de outras ou aos seus próprios. ${ }^{12}$

Entretanto, quando as mulheres passam a fazer a doação, elas adquirem um conhecimento mais aprofundado sobre os BLH. Conforme as mulheres doadoras, o principal motivo para o profissional encaminhá-la a procurar os BLH é para aliviar alguns desconfortos físicos relacionados à lactação, quando elas os apresentam. Mas, à medida que vão tendo contato com o BLH, os objetivos e benefícios do serviço ficam mais claros. ${ }^{12}$

Em um estudo, os autores observaram que, após receberem curso de capacitação sobre aleitamento materno e sobre o BLH, os profissionais assumiram uma postura reflexiva em relação à forma de assistir a mulher que amamenta. ${ }^{4}$

Outro estudo demonstrou que, após participarem de programas de sensibilização e capacitação, profissionais da ESF conseguiram recrutar um percentual significativo de mulheres para a doação de leite humano. ${ }^{9}$ Os profissionais que orientaram as puérperas durante o pré-natal sobre doação de leite materno para os BLH valorizaram a promoção e o incentivo à amamentação, contribuindo para a saúde da criança e da família, bem como para a melhoria da qualidade de vida da população. ${ }^{9}$

As doadoras, as equipes de saúde e o próprio SUS são atores que fazem a RNBLH interagir com o meio social. ${ }^{15}$ A geração e o compartilhamento de conhecimentos entre esses atores são importantes para o desenvolvimento e melhoria da RNBLH; no entanto, essa ação colaborativa ainda é muito incipiente. ${ }^{15}$

Assim, é indispensável reorientar as políticas públicas de saúde no Brasil para a promoção, proteção, apoio e incentivo ao aleitamento materno e à doação de leite humano. ${ }^{10}$ Fazem-se necessárias açóes intersetoriais e integrais para fortalecer a RNBLH. Os atores envolvidos, integrantes diretos ou indiretos do processo, devem manter relaçóes constantes entre si, estabelecendo os nós dos relacionamentos. ${ }^{4}$

\section{Considerações finais}

Os BLH, organizados no Brasil por meio da RNBLH, representam uma estratégia importante para a amamentação e para a manutenção do aleitamento dos bebês que não podem mamar no peito. Essas açóes repercutem positivamente na redução da mortalidade desses públicos-alvo.

Acreditamos ser a intersetorialidade o meio mais acertado para se conseguir a operacionalização de diversas açóes. No tocante à RNBLH, é imprescindível o envolvimento dos diversos atores e o estreitamento da relação entre eles. Porém, os estudos analisados neste artigo mostraram uma fragilidade nessa relação. Urge a necessidade de se estabelecer uma visão holística entre esses sujeitos, não existindo peças isoladas dentro do processo.

A comunicação e a parceria entre os BLH e as Unidades Saúde da Família são incipientes, não sendo de fato efetivas. Ficou claro que muito mais poderia ser conseguido. Acredita-se que, com parcerias efetivas entre os diversos profissionais, o número de doadoras poderia aumentar, proporcionando a manutenção e a melhoria da atuação dos BLH graças ao aumento da doação de leite e da estocagem, o que, por consequência, garante a melhoria da atenção à saúde das crianças, das mães e de toda população.

O número de publicaçóes sobre a temática é reduzido, o que nos sugere a necessidade de se aprofundarem os questionamentos por meio de outros estudos e de se buscar conhecer junto aos profissionais de saúde, bem como às instituiçôes referenciadas, quais as potencialidades e as dificuldades vivenciadas na inter-relação entre eles, cujo sucesso muito tem a contribuir em favor da vida dos recém-nascidos.

\section{Referências}

1. Silva SL. Alegações maternas para a doação do leite humano [dissertação]. Recife: Universidade Federal de Pernambuco; 2010.70 p.

2. Giugliani ERJ. Aleitamento materno: uma contribuição científica para prática do profissional de saúde. J Pediatria. (Rio J). 2004;80(5 Suppl):s117-s118. http://dx.doi.org/10.1590/S0021-75572004000700001.

3. Ministério da Saúde (BR), Agência Nacional de Vigilância Sanitária (ANVISA). Resolução-RDC, n 171, de 4 de setembro de 2006. Dispõe sobre o Regulamento Técnico para o funcionamento de Bancos de Leite Humano. Diário Oficial da União. 2008 Sep 26; Seção 1:33. Disponível em: http://bvsms.saude.gov.br/bvs/saudelegis/anvisa/2006/res0171_04_09_2006.html. 
4. Maia PRS, Almeida JAG, Novak FR, Silva DA. Rede nacional de bancos de leite humano: gênese e evolução. Rev Bras Saúde Mater Infant. 2006;6(3):285-292. http://dx.doi.org/10.1590/S1519-38292006000300004.

5. Rede Nacional de Bancos de Leite Humano [Internet]. Rio de Janeiro: FIOCRUZ; c2005 [acesso em 2011 Jan 20]. Disponível em: http://www.fiocruz.br/redeblh.

6. Ministério da Saúde (BR), Secretaria de Atenção à Saúde, Área técnica de saúde da mulher. Pré-natal e puerpério: uma atenção humanizada e qualificada. Manual Técnico. Brasília, 2006. 163 p. (Série A. Normas e Manuais Técnicos. Série Direitos Sexuais e Direitos Reprodutivos, caderno $\left.n^{\circ} 5\right)$.

7. Almeida JAP, Novak FR. O papel dos bancos de leite humano no incentivo ao aleitamento materno. In: Rego JD, editors. Aleitamento Materno. São Paulo: Atheneu; 2002. p. 321-332.

8. Silva LRM. Conhecimento quanto à doação de leite humano: o que sabem as lactantes? [monografia]. Capina Grande: Curso de Enfermagem, Faculdade de Campina Grande; 2009.

9. Felipe SF, Almeida MFPV. A orientação e Incentivo da doação de leite materno para os bancos de leite durante o pré-natal. Rev Pesq: cuidado é fundamental. (Rio J). 2005;9(1/2):49-56.

10. Alencar LCE, Seidl EMF. Doação de leite humano: experiências de mulheres doadoras. Rev Saúde Pública. 2009;43(1):70-77. http://dx.doi.org/10.1590/S0034-89102009000100009.

11. Alencar LCE, Seidl EMF. Doação de leite humano e apoio social: relatos de mulheres doadoras. Rev Latino-Am de Enfermagem. 2010;18(3):381-389. http://dx.doi.org/10.1590/S0104-11692010000300013.

12. Galvão MTG, Vasconcelos SG, Paiva SS. Mulheres doadoras de leite humano. Acta Paul Enferm. 2006;19(2):157-161. http://dx.doi.org/10.1590/S0103-21002006000200006.

13. Barbosa NB, Silveira MMM. Aleitamento Materno no Município de Anapólis: Saberes e práticas na estratégia saúde da família. Revista APS 2010;13(4):445-455.

14. Ministério da Saúde (BR), Secretaria de Atenção à Saúde, Departamento de Atenção Básica. Guia prático do agente comunitário de saúde. Brasília: Ministério da Saúde; 2009. 260 p.

15. Maia PRS, Novak FR, Almeida JAG, Silva DA. Bases conceituais para uma estratégia de gestão: o caso da Rede Nacional de Bancos de Leite Humano. Cad Saúde Pública. 2004;20(6):1700-1708. http://dx.doi.org/10.1590/S0102-311X2004000600029. 